\title{
Promomycin, a polyether promoting antibiotic production in Streptomyces spp.
}

\author{
Sho-ichi Amano ${ }^{1}$, Tatsuya Morota ${ }^{1}$, Yu-ki Kano ${ }^{1}$, Hiroyuki Narita ${ }^{1}$, Tohko Hashidzume ${ }^{1}$, Setsuya Yamamoto ${ }^{1}$, \\ Kotaro Mizutani ${ }^{1}$, Shohei Sakuda ${ }^{2}$, Kazuo Furihata ${ }^{2}$, Hatsumi Takano-Shiratori ${ }^{1}$, Hideaki Takano ${ }^{1}$, \\ Teruhiko Beppu ${ }^{1}$ and Kenji Ueda ${ }^{1}$
}

Widespread interspecific stimulation of antibiotic production occurs in strains of Streptomyces owing to the activity of diffusible substances, as previously determined in our investigations of the cross-feeding effect. In this study, we newly isolated a substance produced by a Streptomyces strain closely related to Streptomyces scabrisporus, based on the observation that this substance induced the production of an unknown antibiotic in another strain related to Streptomyces griseorubiginosus. This substance, named promomycin, is a polyether structurally related to lonomycin. Promomycin itself had an antibiotic activity, but it stimulated antibiotic production in multiple Streptomyces strains at sub-inhibitory concentrations. Evidence implies that this stimulation effect is widespread within this group of bacteria.

The Journal of Antibiotics (2010) 63, 486-491; doi:10.1038/ja.2010.68; published online 23 June 2010

Keywords: antibiotic production; ionophore; polyether; promomycin; Streptomyces

\section{INTRODUCTION}

Antibiotic production in Streptomyces is affected by various environmental stimuli. ${ }^{1}$ Accumulating evidence has shown that specific diffusible metabolites in addition to physicochemical stimuli induce antibiotic production in Streptomyces. Such metabolites include $\gamma$ butyrolactone autoregulators, which are the best-characterized hormonal signals in Streptomyces and are widely distributed among members of this genus. Since the discovery of A-factor (2-isocapryloyl $3 R$-hydroxymethy- $\gamma$-butyrolactone), secondary metabolism in Streptomyces has been shown to be generally controlled by this type of signal produced by the organism itself. ${ }^{2}$ Both structural diversity and ligandreceptor specificity indicate that $\gamma$-butyrolactone sensing occurs in an intraspecific manner, rather than in an interspecific manner.

In contrast to the concept of autoregulation, our previous observations have shown that interspecific stimulation of secondary metabolism and/or morphogenesis takes place among various Streptomyces species and other related bacteria. ${ }^{3}$ Cross-feeding assays on solid media (see Figure 1a as a reference) have shown that an array of colonies of one strain (corresponding to strain 574 in Figure 1a) responded to a concentration gradient of a substance diffusing from the colony of another strain (corresponding to strain 153 in Figure 1a). To determine whether such stimulatory events between different species involve unknown specific metabolites, we have attempted to isolate the metabolites responsible for the stimulatory activity. We recently identified desferrioxamines, which represent a class of siderophores widely produced by Streptomyces, as an example of such metabolites. ${ }^{4}$

In this study, we explore another interspecific stimulatory event involved in antibiotic production (antibiosis). Structural analyses of a newly isolated antibiosis-promoting substance revealed that this substance is a polyether antibiotic structurally related to lonomycin and mutalomycin. Interestingly, the promotion of antibiotic production occurred at subinhibitory doses of this substance.

\section{MATERIALS AND METHODS}

Bacterial strains and growth conditions

All strains of Streptomyces spp. described in this paper were newly isolated from soil by using the standard isolation technique for this group of bacteria and a medium containing humic acids. ${ }^{5}$ To observe the promotion of antibiosis, strains were grown in Bennett's/glucose medium ( $\mathrm{pH} 7.2$ ) containing $1.0 \mathrm{gl}^{-1}$ yeast extract (Difco, Detroit, MI, USA), $1.0 \mathrm{gl}^{-1}$ fish meat extract (Kyokuto, Tokyo, Japan), $2.0 \mathrm{gl}^{-1} \mathrm{NZ}$ amine (Wako Pure Chemicals, Osaka, Japan) and glucose (Kokusan, Tokyo, Japan). Agar (1.5\%; Kokusan) was added to prepare a solid medium. Antibiotic activity was visualized by growth inhibition of Bacillus subtilis ATCC 6633. To isolate the antibiosis-promoting substance, Streptomyces sp. strain 153 was cultured in a 30-1 jar fermentor (MSJ-U2, Marubishi, Tokyo, Japan). Strain 153 was precultured in $160 \mathrm{ml}$ of Bennett's/glucose liquid medium in a $500-\mathrm{ml}$ Erlenmeyer flask $\left(28^{\circ} \mathrm{C}, 3\right.$ days; rotary shaking at 180 r.p.m. $)$. The preculture was then inoculated into the fermentor containing 201 Bennett's/glucose liquid medium, and cultivated at $28^{\circ} \mathrm{C}$ for 3 days with agitation at 100 r.p.m. The resultant culture broth was centrifuged at $9000 \times g$ for 20 min to obtain culture supernatant.

\footnotetext{
${ }^{1}$ Life Science Research Center, College of Bioresource Sciences, Nihon University, Fujisawa, Kameino, Japan and ${ }^{2}$ Department of Applied Biological Chemistry, Graduate School of Agriculture and Life Sciences, University of Tokyo, Bunkyo-ku, Tokyo, Japan

Correspondence: Dr K Ueda, Life Science Research Center, College of Bioresource Sciences, Nihon University, 1866 Kameino, Fujisawa, Kanagawa 252-8510, Japan.

E-mail: ueda.kenj@@ihon-u.ac.jp

This original article is submitted to the special issue of $J$ Antibiot celebrating $D r$ Arnold Demain's 60 years of scientific career.

Received 7 April 2010; revised 12 May 2010; accepted 27 May 2010; published online 23 June 2010
} 
a

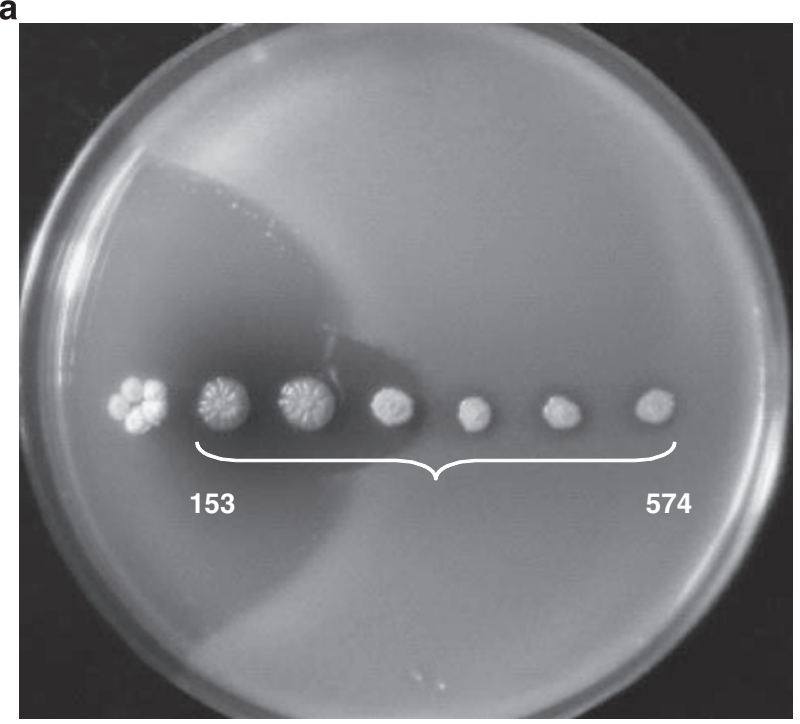

b
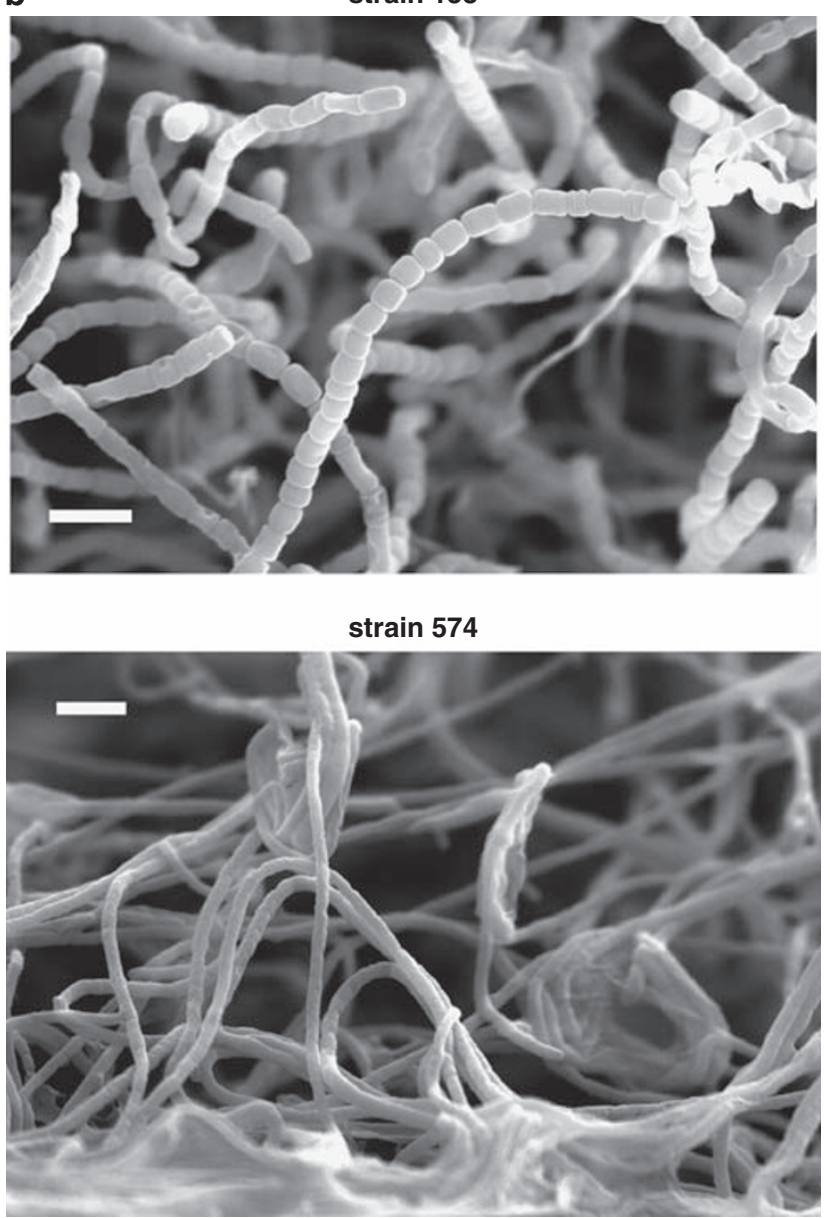

Figure 1 Macroscopic and microscopic view of the two Streptomyces strains used in this study. (a) Cross-feeding assay. Strain 574 was grown as several colonies on Bennett's/glucose agar to observe their response to the concentration gradient of the substance diffusing from a colony of strain 153 . The photograph was taken after 5 days of cultivation at $28^{\circ} \mathrm{C}$ for Streptomyces strains and overnight incubation at $37^{\circ} \mathrm{C}$ for $B$. subtilis. (b) Scanning electron micrographic observation of the colonies. Cells were observed after 5 days of cultivation at $28^{\circ} \mathrm{C}$. Scale bar $=5 \mu \mathrm{m}$.

\section{Isolation of antibiosis-promoting substance}

A volume of approximately 151 of culture supernatant of strain 153 was added to $500 \mathrm{ml}$ of Diaion HP-20 resin (Mitsubishi Chemical Corporation, Tokyo, Japan) to adsorb the metabolite. The resin was washed first with water and then with water containing $30 \%$ acetone. The active metabolite was eluted either with water containing $50 \%$ acetone or $100 \%$ acetone. The eluates were combined and concentrated by evaporation. The $\mathrm{pH}$ was adjusted to 3.0 with $1 \mathrm{~N} \mathrm{HCl}$, and the solution was then extracted with ethyl acetate. The ethyl acetate extract was evaporated to dryness, dissolved in $1 \mathrm{ml}$ chloroform and subjected to the following column chromatography steps using a Purif-compact chromatography system (Moritex, Tokyo, Japan) operated at a flow rate of $5 \mathrm{ml} \mathrm{min}^{-1}$. First, the chloroform solution was applied to a silica-gel column (Purif-pack silicagel; $60 \mu \mathrm{m}$, size 60; Moritex) and eluted with chloroform. The eluate was evaporated to dryness, dissolved in $1 \mathrm{ml}$ chloroform and applied to the same silica-gel column. The column was developed with a gradient of $0-40 \%$ methanol in chloroform. The active fractions were combined and evaporated to dryness, dissolved in $1 \mathrm{ml}$ of methanol and applied to a reversephase column (Purif-pack ODS; $100 \mu$, size 60; Moritex). The column was developed with a gradient of $50-100 \%$ methanol in water. The active fractions were combined and lyophilized, dissolved in $1 \mathrm{ml}$ methanol and applied to the same silica-gel column described above. The column was developed with a gradient of acetone and $n$-hexane at ratios of 2:8-10:0. The active fractions were combined and evaporated to dryness, dissolved in $1 \mathrm{ml}$ methanol and applied to the same reverse-phase column described above. The column was developed with a gradient of $80-100 \%$ acetonitrile in water. The active fractions were combined and lyophilized to obtain the purified active metabolite. By this process, $23.5 \mathrm{mg}$ of the purified substance (1) was obtained from 1001 of culture broth of strain 153.

1: ESI-TOFMS (negative) $m / z 811(\mathrm{M}-\mathrm{H})^{-}$; NMR spectra: Table 1, Supplementary Figure S1 (1H NMR), Supplementary Figure S2 $\left({ }^{13} \mathrm{C}\right.$ NMR), Supplementary Figure S3 (DQFCOSY), Supplementary Figure S4 (HMQC), Supplementary Figure S5 (HMBC).

\section{Phylogenetic analysis}

Each Streptomyces strain was subjected to phylogenetic characterization using a conventional 16S rRNA gene-based analysis. Genomic DNA was extracted using a bacterial genomic DNA purification kit (Edge BioSystems, Gaithersburg, MD, USA) according to the manufacturer's instructions. The 1.5-kb $16 \mathrm{~S}$ rRNA gene fragments were amplified by PCR using the universal bacterial primers B8F (5'-AGAGTTTGATCCTGGCTCAG; nt 8-27 based on Escherichia coli numbering) and B1492R (5'-GGTTACCTTGTTACGACTT; nt 1510-1492 based on E. coli numbering). PCR was performed in a T1 Thermocycler (Biometra, Göettingen, Germany) using Ex Taq polymerase (Takara Shuzo, Kyoto, Japan) under conditions recommended by the manufacturer. The PCR cycle included an initial denaturation period of $5 \mathrm{~min}$ at $94^{\circ} \mathrm{C}$; 30 cycles at $94{ }^{\circ} \mathrm{C}$ for $1 \mathrm{~min}, 55^{\circ} \mathrm{C}$ for $1 \mathrm{~min}, 72^{\circ} \mathrm{C}$ for $1 \mathrm{~min}, 72^{\circ} \mathrm{C}$ for $3 \mathrm{~min}$; and incubation at $4{ }^{\circ} \mathrm{C}$. The PCR amplicons were purified using the Gene Clean Kit II (Funakoshi, Tokyo, Japan) and were directly sequenced using the BigDye Terminator v3.1 cycle sequencing kit in an ABI 3100 automated DNA sequencer (Applied Biosystems, Foster city, CA, USA).

For the construction of a phylogenetic tree, the 16S rRNA gene sequences were compared with those included in the GenBank/EMBL/DDBJ nucleotide sequence databases by using the BLASTN program (http://www.ncbi.nlm.nih. gov/BLAST/). The sequences were aligned using the ClustalW program. ${ }^{6}$ Neighbour-joining phylogeny ${ }^{7}$ was constructed using the NJ plot program, ${ }^{8}$ and bootstrapping ${ }^{9}$ was used to estimate the reliability of the phylogenetic reconstructions (1000 replicates).

\section{RESULTS}

Promotion of antibiotic production by cross-feeding

Figure 1a shows the cross-feeding assay between strains 153 and 574 on Bennett's/glucose solid medium. Strain 574 produced an antibiotic, which inhibited the growth of $B$. subtilis when strain 574 was grown in close proximity to strain 153. It appeared likely that a diffusible substance produced by strain 153 promotes antibiotic production in strain 574 in a concentration gradient-dependent manner. In fact, a 
Table 1 NMR assignments of $1^{\text {a }}$

\begin{tabular}{|c|c|c|c|c|}
\hline C-No. & $\delta_{C}$ & $\delta_{H}$ & $\mathrm{H}-\mathrm{H} \operatorname{COSY}$ & $H M B C(H \rightarrow C)^{b}$ \\
\hline 1 & 179.49 & & & \\
\hline 2 & 46.30 & 2.69 & $\mathrm{H}-40$ & \\
\hline 3 & 101.99 & & & \\
\hline 4 & 36.45 & 1.88 & $\mathrm{H}-39,5$ & \\
\hline 5 & 83.60 & 3.26 & $\mathrm{H}-6,4$ & \\
\hline 6 & 32.90 & 2.20 & $\mathrm{H}-38,5$ & \\
\hline 7 & 73.69 & 3.71 & $\mathrm{H}-8$ & C-3 \\
\hline 8 & 37.52 & 1.74 & $\mathrm{H}-37,9,7$ & \\
\hline 9 & 71.48 & 3.92 & $\mathrm{H}-8$ & C-13 \\
\hline 10 & 34.82 & 2.15 & $\mathrm{H}-36,11$ & \\
\hline 11 & 81.73 & 3.29 & $\mathrm{H}-12 \mathrm{a}, 12 \mathrm{~b}, 10$ & C-13 \\
\hline \multirow[t]{2}{*}{12} & 33.58 & $1.83(\mathrm{Ha})$ & $\mathrm{H}-12 \mathrm{~b}, 11$ & C-13 \\
\hline & & $1.78(\mathrm{Hb})$ & $\mathrm{H}-12 \mathrm{a}, 10$ & C-13 \\
\hline 13 & 107.37 & & & \\
\hline \multirow[t]{2}{*}{14} & 41.03 & $1.88(\mathrm{Ha})$ & $H-15 a, 15 b, 14 b$ & C-13 \\
\hline & & $1.83(\mathrm{Hb})$ & $\mathrm{H}-15 \mathrm{a}, 15 \mathrm{~b}, 14 \mathrm{a}$ & C-13 \\
\hline \multirow[t]{2}{*}{15} & 32.67 & $2.00(\mathrm{Ha})$ & $H-15 b, 14 a, 14 b$ & \\
\hline & & $1.64(\mathrm{Hb})$ & $\mathrm{H}-15 \mathrm{a}, 14 \mathrm{a}, 14 \mathrm{~b}$ & \\
\hline 16 & 88.31 & & & \\
\hline 17 & 82.68 & 3.78 & $\mathrm{H}-18 \mathrm{a}, 18 \mathrm{~b}$ & \\
\hline \multirow[t]{2}{*}{18} & 28.94 & $1.84(\mathrm{Ha})$ & H-19a, 19b, 18b, 17 & \\
\hline & & $1.71(\mathrm{Hb})$ & H-19a, 19b, 18a, 17 & \\
\hline \multirow[t]{2}{*}{19} & 34.64 & $2.09(\mathrm{Ha})$ & $\mathrm{H}-19 \mathrm{~b}, 18 \mathrm{a}, 18 \mathrm{~b}$ & \\
\hline & & $1.53(\mathrm{Hb})$ & $\mathrm{H}-19 \mathrm{a}, 18 \mathrm{a}, 18 \mathrm{~b}$ & \\
\hline 20 & 85.92 & & & \\
\hline 21 & 87.86 & 3.95 & $\mathrm{H}-22$ & \\
\hline 22 & 36.94 & 2.31 & $\mathrm{H}-33,23 \mathrm{a}$ & \\
\hline \multirow[t]{2}{*}{23} & 34.64 & $2.26(\mathrm{Ha})$ & $\mathrm{H}-24,23 b, 22$ & \\
\hline & & $1.53(\mathrm{Hb})$ & $\mathrm{H}-24,23 \mathrm{a}$ & \\
\hline 24 & 78.63 & 4.27 & $\mathrm{H}-25,24 \mathrm{a}, 24 \mathrm{~b}$ & C-21, 25 \\
\hline 25 & 76.40 & 3.42 & H-26, 24 & C-29 \\
\hline 26 & 40.82 & 1.32 & $\mathrm{H}-32, \mathrm{H}-27$ & \\
\hline 27 & 86.15 & 2.91 & $\mathrm{H}-28, \mathrm{H}-26$ & \\
\hline 28 & 47.57 & 1.52 & $\mathrm{H}-31,27$ & \\
\hline 29 & 102.19 & & & \\
\hline 30 & 22.20 & 1.27 & & C-28, 29 \\
\hline 31 & 12.62 & 1.01 & $\mathrm{H}-28$ & C-28, 29 \\
\hline 32 & 13.42 & 0.98 & $\mathrm{H}-26$ & C-25, 26, 27 \\
\hline 33 & 16.41 & 0.97 & $\mathrm{H}-22$ & $C 23,24,25$ \\
\hline 34 & 23.60 & 1.17 & & $\mathrm{C}-17,19,20,21$ \\
\hline 35 & 25.00 & 1.23 & & $\mathrm{C}-15,16,17$ \\
\hline 36 & 12.18 & 0.85 & $\mathrm{H}-10$ & $\mathrm{C}-9,10,11$ \\
\hline 37 & 13.70 & 0.92 & $\mathrm{H}-8$ & C-7, 8, 9 \\
\hline 38 & 5.21 & 0.81 & $\mathrm{H}-6$ & $C-5,6,7$ \\
\hline 39 & 11.97 & 0.96 & $\mathrm{H}-4$ & $C-3,4,5$ \\
\hline 40 & 12.27 & 1.19 & $\mathrm{H}-2$ & $C-1,2,3$ \\
\hline 5-OMe & 56.32 & 3.31 & & $\mathrm{C}-5$ \\
\hline 11-OMe & 56.54 & 3.35 & & C-11 \\
\hline 27-OMe & 59.26 & 3.40 & & C-26, 27 \\
\hline 29-OMe & 48.24 & 3.16 & & C29 \\
\hline
\end{tabular}

aspectra were obtained in $\mathrm{CD}_{3} \mathrm{OD}$ on a Varian Unity INOVA 500 (Variant Technologies, Tokyo, Japan).

bKey correlations necessary for structural analysis.

preliminary study showed that an ethyl acetate extract of the culture broth of strain 153 stimulated antibiotic production in strain 574 (data not shown). Strain 574 also produced an intracellular yellow pigment in response to the putative stimulatory substance produced by strain 153 (Figure 1a). Strain 153 produced an antibiotic in a manner independent of the presence of strain 574 (data not shown).
Scanning electron microscopy showed that the cells of both strains exhibited morphology typical of Streptomyces. While strain 153 formed abundant spore chains, strain 574 only grew as substrate mycelium on Bennett's/glucose solid medium. Phylogenetic analysis based on the 16S rRNA gene sequences demonstrated that strains 153 and 574 are closely related to Streptomyces scabrisporus and Streptomyces griseorubiginosus, respectively, with sequence identities greater than 99\% (Figure 2).

\section{Isolation and structural determination of an antibiosis-promoting substance}

The antibiosis-promoting substance isolated from the culture broth of strain 153, as described in Materials and Methods, was named promomycin (1), based on the promotion of antibiotic production. Analysis of DQFCOSY and HMBC spectra of 1 (Table 1) clarified the connections from $\mathrm{C}-1$ to $\mathrm{C}-30$ and enabled construction of the main carbon chain of 1 . The positions of the 10 methyl and 4 methoxy groups were also determined at C-2, 4, 6, 8, 10, 16, 20, 22, 26 and 28 and at C-5, 11, 27 and 29 by the 2D NMR spectra. Thus, locations of all 44 carbon atoms observed in the ${ }^{13} \mathrm{C}$ NMR spectrum of 1 were clarified. Furthermore, long-range couplings between $\mathrm{C}-3$ and the methine proton at C-7; C-13 and the methine proton at C-9; C-17 and methyl protons at C-34; C-21 and the methine proton at C-24; plus $\mathrm{C}-29$ and the methine proton at C-25 showed the formation of ether linkages between C-3 and C-7; C-9 and C-13; C-17 and C-20; C-21 and C-24; C-25 and C-29, respectively. These structural features and the molecular weight of $\mathbf{1}$ (812) estimated from the ESI-TOF-MS spectrum strongly provide evidence of a polyether structure, which is similar to that of lonomycin (Figure 3). The ether linkage between C-13 and C-16 was not revealed by NMR analysis of 1 , but comparisons of $\delta_{\mathrm{c}}$ values assigned for lonomycin with those of 1 clearly indicated that the C-9-C-16 moiety of $\mathbf{1}$ has the same spiroether structure as that of lonomycin. ${ }^{10}$ Thus, the structure of promomycin was determined as $\mathbf{1}$.

The structure of $\mathbf{1}$ is a methanol adduct of A80438. A80438 is an antibiotic, which was previously described in a patent, ${ }^{11}$ but its NMR data have not been reported. A80438 and its congeners, lonomycin and mutalomycin, have the same stereochemistry, but it is not clear if $\mathbf{1}$ shares this stereochemistry. The assignments of protons and carbons in the NMR spectra of $\mathbf{1}$ are summarized in Table 1.

\section{Stimulation of antibiotic production by polyethers}

The structure of promomycin is similar to the structures of polyether antibiotics. This suggests that promomycin would also have antibiotic activity. Our tests indicated that it inhibits the growth of B. subtilis when added to growth medium at levels of $8.0 \mu \mathrm{g} \mathrm{ml}^{-1}$ or more (Figure 4a). In contrast, the minimal concentration of promomycin required for the stimulation of antibiotic production in strain 574 was $0.8 \mu \mathrm{g} \mathrm{ml}^{-1}$.

To investigate whether the stimulation of antibiotic production is common among this class of compounds, several commercially available polyethers were also studied to assess their ability to induce antibiotic production in strain 574. As shown in Figure $4 \mathrm{~b}$, a relatively weak but similar antibiosis-promoting activity was observed with regard to salinomycin, monensin and nigercin.

The antibiosis-promoting activity of promomycin was investigated using other Streptomyces strains isolated from soil. Among approximately 200 strains studied, the phenomenon was observed in Streptomyces strains 001, 023 and 555 (Figure 4c). Phylogenetic analysis based on 16S rRNA gene sequences (Figure 2) revealed that both strains 001 and 023 are related to Streptomyces glomeratus 


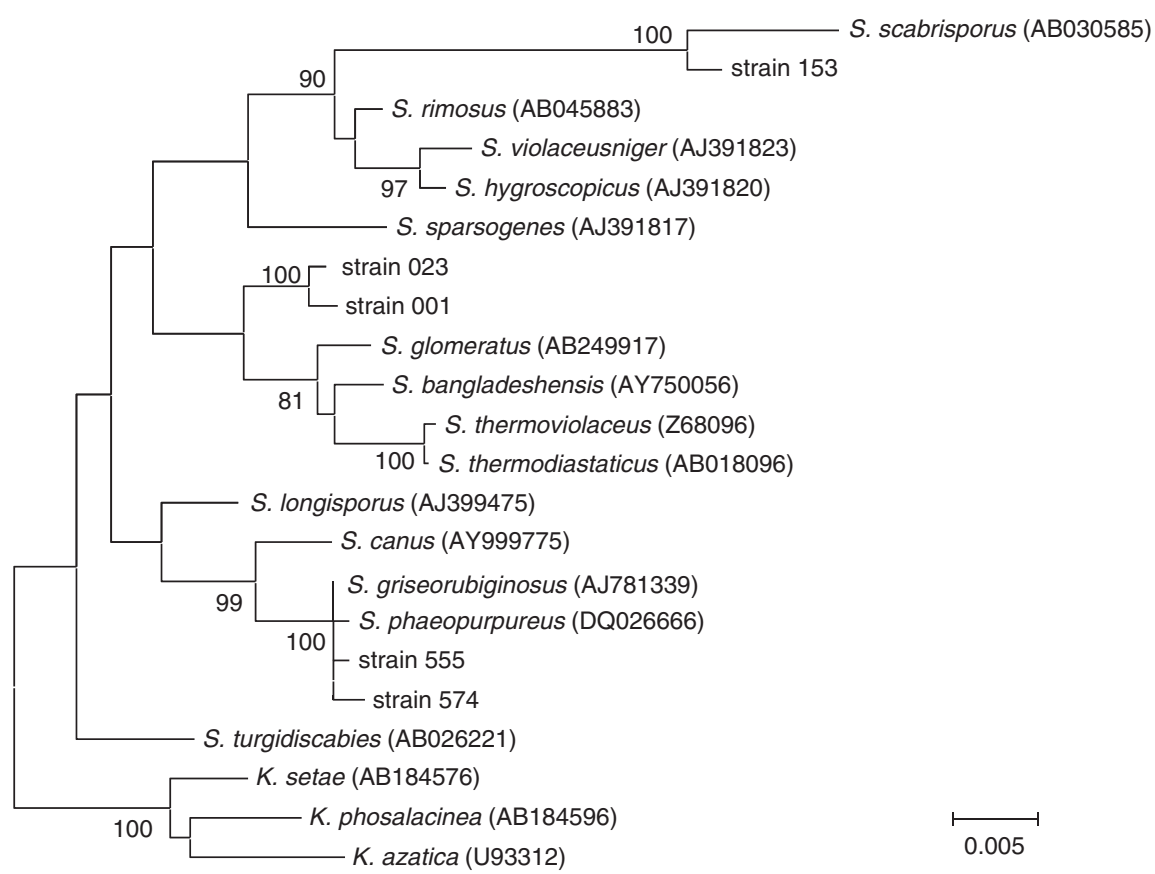

Figure 2 Unrooted tree showing phylogenetic branches of the Streptomyces isolates described in this study, with respect to the 16S rRNA gene. The tree, constructed by the neighbour-joining method, was based on a comparison of the aligned positions of 1200 nucleotides. Each bootstrap value is expressed as a percentage of 1000 replications, and values above $70 \%$ are provided at the branching points. Kitasatospora spp. are used as an outgroup. Scale bar=0.5\% sequence divergence.

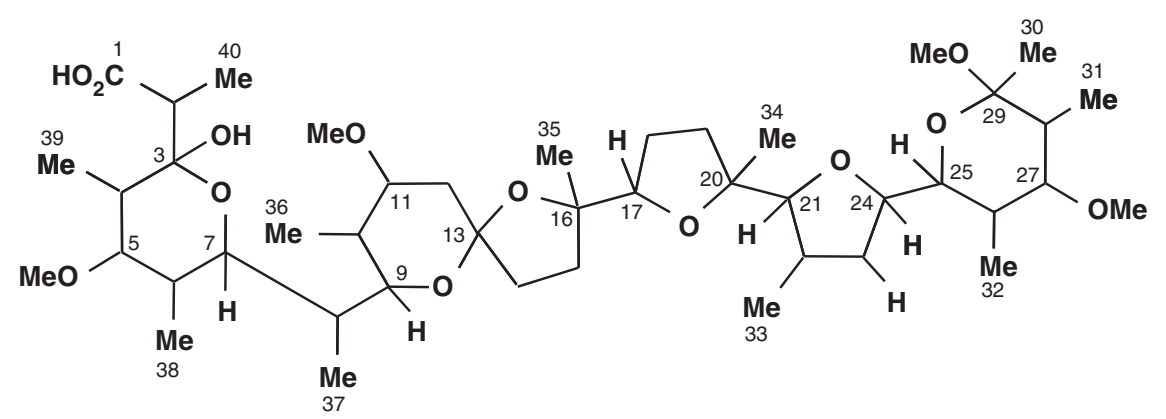

Promomycin (1)

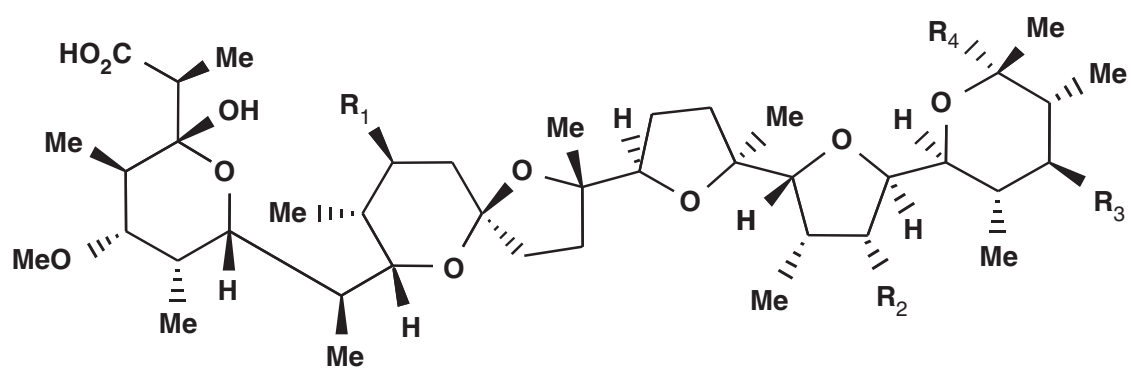

$$
\begin{array}{ll}
\text { A80438 } & \mathrm{R}_{1}=\mathrm{OCH}_{3}, \mathrm{R}_{2}=\mathrm{H}, \mathrm{R}_{3}=\mathrm{OCH}_{3}, \mathrm{R}_{4}=\mathrm{OH} \\
\text { Lonomycin } & \mathrm{R}_{1}=\mathrm{OCH}_{3}, \mathrm{R}_{2}=\mathrm{OCH}_{3}, \mathrm{R}_{3}=\mathrm{OCH}_{3}, \mathrm{R}_{4}=\mathrm{OH} \\
\text { Mutalomycin } & \mathrm{R}_{1}=\mathrm{OCH}_{3}, \mathrm{R}_{2}=\mathrm{H}, \mathrm{R}_{3}=\mathrm{H}, \mathrm{R}_{4}=\mathrm{OH}
\end{array}
$$

Figure 3 Chemical structure of promomycin and related compounds.

and its close relatives (sequence identity 98\%), and that strain 555 is closely related to S. griseorubiginosus (sequence identity 99\%) as is strain 574 .

\section{DISCUSSION}

This study revealed that promomycin, a new polyether antibiotic produced by a Streptomyces strain closely related to S. scabrisporus, 
a

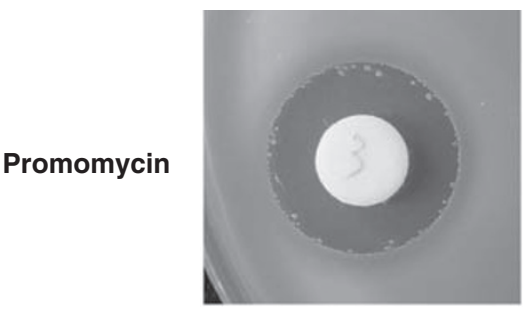

b
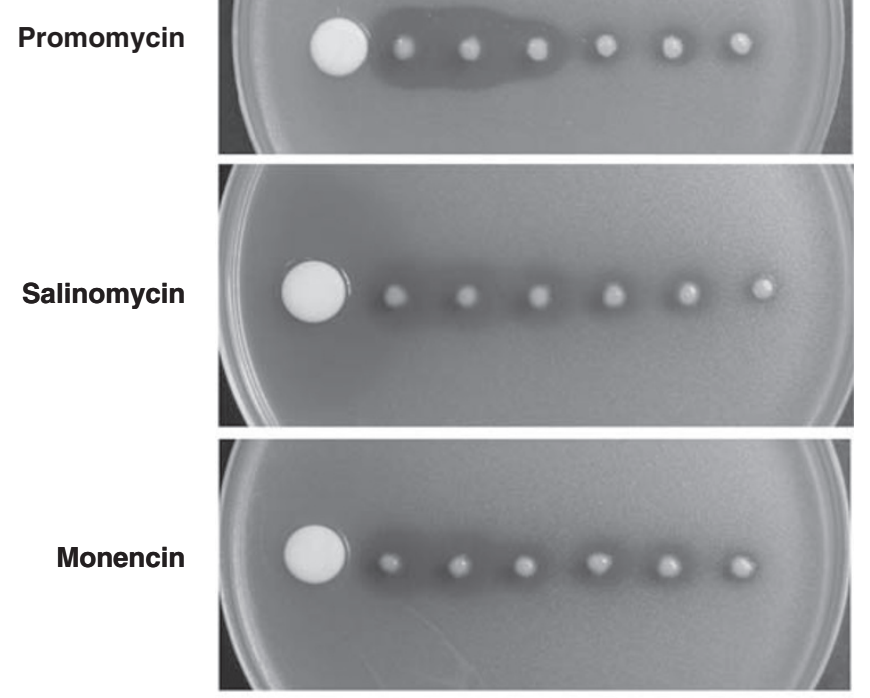

Nigericin

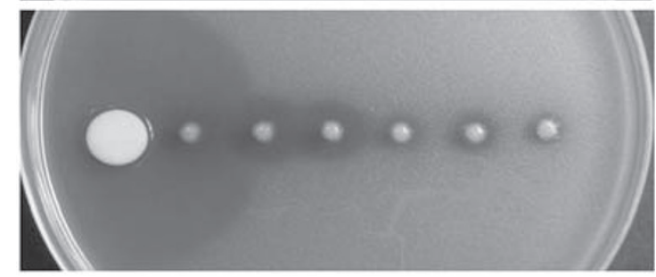

C

strain 001

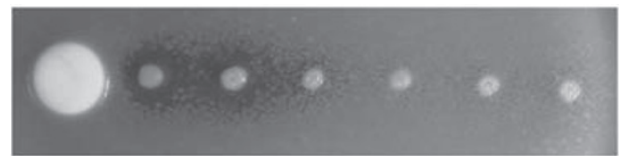

strain 023

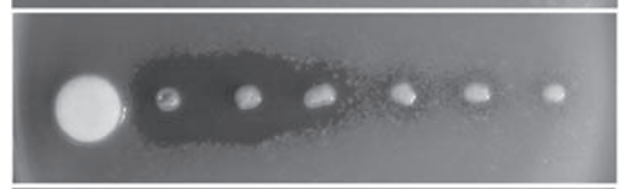

strain 555

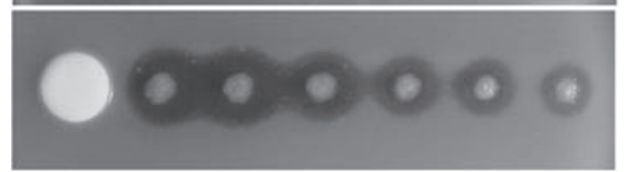

Figure 4 Effects of polyether antibiotics. (a) Growth inhibition of $B$. subtilis by diffusion of promomycin from a filter disc containing $0.5 \mu \mathrm{g}$ of promomycin. (b) Promotion of antibiotic production in strain 574 by promomycin and other commercially available polyether antibiotics. Each disc contained promomycin $(0.5 \mu \mathrm{g})$, salinomycin $(0.5 \mu \mathrm{g})$, monencin $(1.0 \mu \mathrm{g})$ and nigericin $(1.0 \mu \mathrm{g})$. (c) Stimulation of antibiotic production by promomycin in other strains. Discs contained promomycin at $250 \mathrm{ng}$ (for strains 001 and 555) or $50 \mathrm{ng}$ (for strain 023). All patches were photographed after 5 days of cultivation on Bennett's/glucose solid medium at $28^{\circ} \mathrm{C}$ for Streptomyces strains and overnight incubation at $37^{\circ} \mathrm{C}$ for $B$. subtilis. induces production of an antibiotic in another strain related to S. griseorubiginosus. Promomycin is structurally related to lonomycin and derivatives produced by various Streptomyces spp., including Streptomyces ribosidificus and Streptomyces mutabilis. ${ }^{12,13}$ These findings lead us to propose that similar stimulation of secondary metabolite production may also occur based on the activity of this type of polyether produced by these species. Furthermore, the similar stimulation caused by other polyether antibiotics (Figure $4 \mathrm{~b}$ ) implies that the phenomenon may occur widely within bacteria producing this family of compounds. The structural diversity of these polyethers supports the view that the stimulation of antibiotic production observed in this study is not a result of co-synthesis (that is, production achieved by using the polyether as a substrate) but instead is related to de novo synthesis of the antibiotic.

Apart from co-synthesis, there is a possibility that the promotion of antibiosis is based on a synergism between the ionophore and an unknown substance produced by strain 574 . To address the issue, we partially purified that antibiotic the production of which is stimulated by the addition of monensin, and observed that it exhibited an antibiotic activity even after its separation from monensin to the same extent as that before separation (our unpublished observation). The antibiotic activity did not exist in the culture without monensin. Hence, we believe that the stimulation of antibiotic activity is due to the action of a newly generated substance, not to an enhancement of the antibiotic activity of monensin.

It is known that polyether antibiotics inhibit bacterial growth by acting as ionophores. ${ }^{14,15}$ Ionophores facilitate the permeation of specific ions across cell membranes by inducing the formation of pores. Lonomycin and related compounds exhibit a high affinity for $\mathrm{K}^{+}$ion. ${ }^{16}$ This suggests that promomycin also affects bacterial growth by facilitating $\mathrm{K}^{+}$efflux. This also raises the possibility that the process of antibiotic production in strain 574 depends on the availability of $\mathrm{K}^{+}$ and that promomycin induces antibiotic production by affecting the intracellular $\mathrm{K}^{+}$concentration. However, we found that elevated $\mathrm{K}^{+}$ concentrations in culture media do not affect the productivity of the antibiotic in this strain (our unpublished observation).

Another possible explanation for the stimulation is that the pores formed by the polyether facilitate the leakage of the antibiotic. Although this possibility should be carefully assessed by detailed biochemical analyses, we think it is relatively unlikely, as we could not detect any antibiotic activity in the intracellular fraction of the untreated cells of strain 574 (our unpublished observation). The fact that antibiotic production of many other strains was not affected by the addition of promomycin may also exclude the possibility that the ionophore facilitates the leakage of relatively large organic compounds.

Another possibility is that promomycin serves as or facilitates the efflux of a signal that stimulates expression of the genes responsible for antibiotic biosynthesis. This is supported by the fact that promomycin induces the production of an intracellular yellow pigment. Our preliminary purification study has indicated that this yellow pigment is distinct from the substance, which inhibits the growth of $B$. subtilis (our unpublished observation). Promomycin may affect the function of a pleiotropic regulator responsible for the expression of multiple biosynthetic pathways in strain 574. Interestingly, promomycin stimulated antibiotic production at a subinhibitory concentration (Figure $4 \mathrm{~b}$ ). This leads us to propose that the mechanism of stimulation is distinct from the mechanism of bactericidal activity. The distinct mechanism may also explain the multiple effects of lonomycin, which exhibits antitoxoplasma activity at a significantly lower concentration $\left(0.01 \mu \mathrm{g} \mathrm{ml}^{-1}\right)$ than that required for the bactericidal activity $\left(\sim 3 \mu \mathrm{g} \mathrm{ml}^{-1}\right){ }^{17}$

The primary function of secondary metabolites has not yet been resolved. Davies and colleagues $^{18}$ have pointed out that certain 
antibiotics exert different effects when supplied at subinhibitory concentrations. In this review, they also refer to Waksman's view that the real role of antibiotics in nature would not be growth inhibition. ${ }^{19}$ Presumably, various actions of small molecules will include unknown effects of antibiotics at subinhibitory concentrations, which constitute complex fundamental interactions among members of the microbial community. Acquiring an understanding of these interactions will be important for the field of microbial ecology. In addition, the phenomenon identified in this study raises the possibility of stimulating the production of new antibiotics by treating strains with polyether activators. Knowledge regarding the diverging effects of small molecules may also have a function in the development of new strategies for microbial screening.

\section{ACKNOWLEDGEMENTS}

We thank Dr Masahiko Takino of Agilent Technologies, Japan, for technical assistance. This study was supported by the High-Tech Research Center Project of the Ministry of Education, Culture, Sports, Science and Technology, Japan, and a grant from the Institute for Fermentation, Osaka.

1 Demain, A. L. Induction of microbial secondary metabolism. Int. Microbiol. 1, 259-264 (1998).

2 Horinouchi, S. Mining and polishing of the treasure trove in the bacterial genus streptomyces. Biosci. Biotechnol. Biochem. 71, 283-299 (2007).

3 Ueda, K. et al. Wide distribution of interspecific stimulatory events on antibiotic production and sporulation among Streptomyces species. J. Antibiot. 53, 979-982 (2000).
4 Yamanaka, K. et al. Desferrioxamine E produced by Streptomyces griseus stimulates growth and development of Streptomyces tanashiensis. Microbiology 151, 2899-2905 (2005).

5 Hayakawa, M. \& Nonomura, H. A new method for the intensive isolation of actinomycetes from soil. Actinomycetologica. 3, 95-104 (1989).

6 Thompson, J. D., Higgins, D. G. \& Gibson, T. J. CLUSTAL W: improving the sensitivity of progressive multiple sequence alignment through sequence weighting, position-specific gap penalties and weight matrix choice. Nucleic Acids Res. 22, 4673-4680 (1994).

7 Saitou, N. \& Nei, M. The neighbor-joining method: a new method for reconstructing phylogenetic trees. Mol. Biol. Evol. 4, 406-425 (1987).

8 Perriere, G. \& Gouy, M. WWW-query: an on-line retrieval system for biological sequence banks. Biochimie. 78, 364-369 (1996).

9 Felsenstein, J. PHYLIP: phylogeny inference package. (version 3.2) Cladistics 5, 164-166 (1989).

10 Seto, H., Mizoue, K. \& Otake, N. Studies on the ionophorous antibiotics. XXXVI The assignments of the ${ }^{13} \mathrm{C}-\mathrm{NMR}$ spectra of lonomycin A and mutalomycin. J. Antibiot. 33, 979-988 (1980).

11 Hamill, R. L., Nakatsukasa, W. M. \& Yao, R. C. (Eli Lilly and Company). Novel polyether anbitiotic A80438 from Streptomyces. U.S. 004824863, April 25 (1989).

12 Fehr, T., King, H. D. \& Kuhn, M. Mutalomycin, a new polyether antibiotic taxonomy, fermentation, isolation and characterization. J. Antibiot. 30, 903-907 (1977).

13 Omura, S., Shibata, M., Machida, S. \& Sawada, J. Isolation of a new polyether antibiotic, lonomycin. J. Antibiot. 29, 15-20 (1976).

14 Butaye, P., Devriese, L. A. \& Haesebrouck, F. Antimicrobial growth promoters used in animal feed: effects of less well known antibiotics on Gram-positive bacteria. Clin. Microbiol. Rev. 16, 175-188 (2003).

15 Westley, J. W. Chemical transformations of polyether antibiotics. in Polyether Antibiotics: Naturally Occurring Acid lonophores (ed Westley, J. W.) 51-87, vol. 2. Chemistry (Marcel Dekker, NY, 1983).

16 Mitani, M. \& Otake, N. Studies on the ionophorous antibiotics. XV The monovalent cation selective ionophorous activities of carriomycin, lonomycin and etheromycin. J. Antibiot. 31, 750-755 (1978).

17 Miyagami, T. et al. An in vitro study on the toxoplasmacidal activity of lonomycin A in host cells. J Antibiot. 34, 218-223 (1981).

18 Yim, G., Wang, H. H. \& Davies, J. Antibiotics as signalling molecules. Philos. Trans. R. Soc. Lond. B. Biol. Sci. 362, 1195-1200 (2007).

19 Waksman, S. A. The role of antibiotics in nature. Perspect. Biol. Med. 4, 271-286 (1961).

Supplementary Information accompanies the paper on The Journal of Antibiotics website (http://www.nature.com/ja) 